decay. In some cases the former has the preponderance, when the surface of the ulcer is raised, granular, or warty, with an everted edge; perhaps the mass shoots forth through the skin as a large and overhanging fungus, or it forms a great tumour extending for a considerable distance under the skin. When, on the other hand, the decay and ulceration proceed rapidly, a large excavation, with raised sharp edges, is the result.

\section{ON THE EXAGGERATION OF IDEAS}

RELATIVE TO

CERTAIN SANITARY TOPICS.

By DANIEL NOBLE, EsQ., M.R.C.S.

Read at the Conversarione of the Royal Institution, Manchester, Dec. 11, 1850.

There exists a power in new ideas which, as the novelty ceases, the ideas themselves do not maintain. Let opinions or conclusions be boldly advanced and perseveringly promulgated at variance with those which, time-honoured though they be, exert but a measured and steady influence upon society, and it will be seen that, for a season, they agitate the minds and determine the actions of their votaries to a degree far beyond what is noticeable in after periods. This is the case with doctrines the truth of which becomes ultimately demonstrated; and yet to a much greater extent with the fleeting vagaries or the half-truths of successive epochs. Undoubtedly this power of novelty is a great fact in universal nature; we recognize it in all classes of phenomena; it is a fact, moreover, everywhere witnessed as qualifying physical, moral, and social agency. Look at the workings of vegetation on the final disappearance of a retarding frost; how notable is the progress when the earth and the air become newly influenced by the genial warmth of a kindly spring. See the energizing influence of great moral truths, observable in so remarkable a manner on first being realized vividly by communities or individuals. We only need for one moment to reflect upon the past history of society to perceive that all its extraordinary commotions and upheavings have been preceded by, and are traceable to, the influence of new ideas. And although this important truth is susceptible of the plainest illustration by adverting to experience on the widest scale, a careful inquiry will yet show us that, in every department of thought and action, even the most minute-the same fact exists; all things attesting, indeed, the unwonted force, the exaggerated influence of ideas in their freshness.

In all matters which involve considerations of life, health, and disease the susceptibility of mankind to the influences of novelty is very striking. Let an idea for instituting improved modes of cure, or for prolonging life, be propounded, with even moderate plausibility, and see how large numbers arise to catch at it. And no experience of the falsehoods or the mischiefs which empiricism exhibits in its successive phases, leads to a popular recognition of its fallacies or its dangers. Each generation witnesses the rise and fall of numerous systems of quackery; yet faith revives always in the latest, and multitudes do it homage. Amulets and sympathetic powders constitute the illustration in one age, as galvanic rings and infinitesimal doses do in another. No matter for the inconsistencies and contrasts which impudently-advanced innovations present, novelty has always its charms for a time. If brandy and salt fail to realize the sanguine expectation of individuals, they will probably seek, with corresponding avidity, for relief in its opposite-cold water. And so it is ever. Newness strikes the ignorance of mankind, and wonder moves the world-a lever more potent than good sense, even in the nineteenth century.

A fact must here be kept in mind :-Whilst the influence of false ideas perishes very generally with their novelty, the power of those which are true for ever endures. Yet these latter display an energy very frequently in their birth which is not permanently sustained. But this phenomenon is further observed. Men becoming newly conscious of some extraordinary agency, proceed in their admiration to invest the source of it with attributes beyond those which are properly its own, just as certain nations of Pagan antiquity were led to imagine that a true divinity inhered in the visible source of light and heat. So what is true becomes overlaid and disfigured by that which is false, and in this way exaggerations arise of notions in themselves not unjust.

The exaggeration of ideas relative to certain sanitary topics, forms at the present period a striking exemplification of much that has been said. Men's minds at this time have become awakened to certain truths of importance-truths of which, twenty-five years ago, the bulk of the nation for all practical purposes was in ignorance the most profound. It must yet be acknowledged that from having, in a former era, attached little or no consideration to the physical conditions upon which health depends, the opposite error would seem now to have place. There is every disposition in the world amongst many to attribute the origin of almost every disease to some defect in the sanitary condition of the place of residence. Ailments with which, from the very nature of the thing, the mere dwelling-house, or the locality, can have had nothing to do, are ascribed very often, in accordance with the fashion of the day, to some possible fault in the drainage or the ventilation. Over-exertion of mind, depressing passions, late hours, irregularity in diet, and silk stockings, are entirely overlooked, whilst the presence of a ditch or a cesspool, some hundreds of yards off, is keenly detected, and possibly referred to as the origin of diseases rightly attributable to the influences ignored. A merchant capitalist has his days and his nights unceasingly harassed by care and anxiety, and suffers of course in his stomach and nervous system; hereupon he persuades himself fondly that all may be remedied, and be in future avoided, by removing a few miles from the town. Fevers and other contagious diseases decimate 
at intervals the population of large places; it is rashly inferred from this circumstance that all such maladies are absolutely extinguishable by what have been called preventive measures-that is to say, by drainage and ventilation. The effects of bad food or scarcity, are but too often left out of the calculation. Indeed the speeches and the writings of some of our sanitary enthusiasts, would lead very near to the hope that all mankind, as the world advances, would die no longer of actual disease, but only of old age. We will contrast the existing state of popular sentiment with that which obtained some twenty years ago, before the public mind was systematically directed to this topic, and then we will attempt to strike a balance, in determination of the position which recent inquiries and discussions have apparently made good. Every one who is of sufficiently mature years will remember that, prior to late investigations, the subject of health in connection with residence was rarely deemed of sufficient consequence to occupy serious attention. The aspect of a house in relation to prevalent winds, the drainage of its neighbourhood, the ventilation of its rooms, or the quality of its water-supplies, only excited attention and thought under speciality of circumstances. When rheumatism seriously enfeebled the head of a family, or consumption deprived it of its flower and its hope, then the importance of a dry atmosphere and free ventilation became practically realized. Epidemic maladies ravaged the impoverished parts of our cities and large towns, but the miserable hovels in which the victims had lived were but little regarded in discussions of a remedy. Everything was believed to have been done if some hospital were established, or some physician sent to see the sick-poor at their own pestilential abodes; I say see, for cure or medical care were impossible under the circumstances. Overcrowding and filth were in ignorance allowed to do their worst, and abominations unspeakable degraded humanity to the level of the brute. For ailments generally, drugs were almost the only aids invoked. The necessity of placing the human organism in some understood harmony with external nature, if health were to be secured, was but little considered. In these respects, indeed, man seemed to know, or at least to think, less of himself than of the lower animals, over whose physical condition the elements were at all times known to exert a paramount influence.

From such a state of practical imbecility the researches of the last few years have aroused the public intelligence. And facts and laws long comprehended in their general bearings by the scientific physiologist, have now been brought home to the consciousness of the many. And persons in exaggerated homage to a new and admired truth, would at this time render almost exclusively important what had heretofore been so much disregarded. Thus it has happened with sanitary topics, as with numerous others, that ideas have been estimated beyond their just value, considered alike in their intrinsic worth and in their extrinsic relations, exemplifying in a striking manner that disposition in the popular mind which subjects it to so largely to the sway of novelty.

It has been established and placed beyond doubt, that towns are less healthy than country places.' It has been shown that the average age of death in the former is lower than in the latter, and that a greater proportionate mortality takes place annually in urban than in rural districts. Further, it has been made certain that epidemic and contagious diseases are much more destructive in towns than in the country. In order, however, that the fundamental truth which these facts disclose should be correctly seized, the facts themselves must be submitted to some analysis; and, this being done, the result is to show that what ordinarily is affirmed of towns generally, is true only of particular localities. Thus, the lower average age of death in towns than in country places, is obtained by including the narrow streets, courts, and alleys, where overcrowding, filth, destitution, drunkenness, and neglect of young children, form causes constantly operative in the destruction of human life. When districts occupied by the middle and more opulent classes are selected for the investigation, to the exclusion of pauperised localities, little or no difference is discoverable between such places and the country. The annual mortality, moreover, under such circumstances, is not proportionately high. And it is a fact, that diseases which diffuse themselves, more especially under bad sanitary conditions, no more spread nor produce greater fatality, in the better parts of a town, than they do in the country. Let the epidemic fever of 1847 furnish the illustration. Typhus, in Manchester, raged during that year with thrice the severity of any visitation of the kind ; yet it never became prevalent in any of our moderately-conditioned streets. If some few individuals became the subjects of attack residing in localities raised above the pauperised, it was from contagion imbibed through habitual attentions to the sick, and from such persons the disease never extended itself. I was furnished myself with unusual opportunities for observing the several circumstances of that memorable epidemic, and I do not know of a single instance where, in Manchester, the fever was transmitted to another from a patient dwelling in any of our better class streets; proving, most amply, that a very moderate ventilation is capable of extinguishing the virulencethe zymotic property-of the typhus poison. It would carry me beyond limits and exceed altogether the present design to enlarge upon this theme. I will simply reiterate the conclusion, that epidemic and contagious diseases neither destroy life, nor imperil the constitution in the well-conditioned parts of a town, more than in rural districts.

Facts and considerations like the foregoing, as well as a more particular and intimate experience, will authorize the assertion that, under the circumstances in which mankind at large are placed, and with reference to the human constitution generally, towns, as such, need not be less healthy than the country; and that, in point of fact, a well-selected dwelling in most of our great towns as they actually exist, will, in an immense majority of instances, be found just as conducive to health and longevity as one that is strictly rural. I say in an immense majority of instances, because, in a subject of this kind, no rule that can be laid down will apply 
universally; the truth being, that, to some constitutions, the country, and to others the town, is the most advantageous. With large numbers the difference is neither to be realized nor appreciated.

That I may make this part of the discussion a little more intelligible, I will briefly state and explain a point of doctrine in physiology, which is this:-True health consists in the harmonious performance of all the functions of life, and harmony in this respect is secured and promoted by adapting the several organs and systems of the body as much as possible to the external conditions upon which their just exercise depends. Thus the lungs need pure air, the stomach good food, and the brain and nervous system require that every influence which affects the consciousness should be agreeable. I do not here state the whole case, but only what the occasion would appear to demand. Now, if there be a defect or a vice in any of the conditions just adverted to, the result must certainly be more or less to injure the health. The effect, from littleness of the cause, may scarcely be appreciable, but undoubtedly some result of a prejudicial character must always ensue from any deviation from the strict requirements of health.

To apply this doctrine. Certain constitutions require more especially that the inspired air should be pure, in order that the health be sustained in full measure ; in such instances, a country residence will generally be found the best. This is most frequently the case in scrofulous habits of body, particularly if the temperament be phlegmatic. Young children almost always flourish more in the country than in towns. It must yet be noted that, in very exposed situations, there is more liability to inflammatory disease, and a greater violence upon its taking place. These countervailing considerations, however, can very well be obviated by corresponding watchfulness and care.

Now, on the other hand, there are persons so constituted, that health depends much more upon moral and social influences than upon any extraordinary advantages affecting the respiration. Such individuals will often enjoy much better health in the town, or the immediate suburbs, than in the country; always supposing that some fair judgment have been exercised in the choice of a dwelling-house. Where the mind is active and the disposition social, the tranquillity of a country life, and its comparative loveliness, operate prejudicially upon the brain and nervous system, and thus health becomes deteriorated at its source. It is under circumstances of this kind, that the invigorating effects of a temporary London life are often witnessed, when dissipation and excess do not antagonize them.

To hard-working persons whose days are actively engaged in the commerce and busy pursuits of a town, it is an unmitigated advantage to have lodgings in the country. Yet, where the permanent residence is rural, the wives and the daughters very often sustain detriment from want of due activity in the brain and nervous system. In such instances there is an absence of that proper succession of agreeable impressions upon the mind, so essential to that harmonious action of the organism which constitutes true health. And so it is universally: human nature must be estimated in its totality in all questions of its well being. The functions severally demand an appropriate pabulum or sustenance, and however excellently disposed may be the external relations of any one portion of the organization, health will fail if the beneficial action of some other be prejudiced.

I will, in this place, reiterate the facts and the inferences which $I$ conceive to have been made out by recent sanitary investigations :-It is the poverty-stricken, over-crowded, and ill-constructed parts of large cities exclusively, that supply the evidence which renders urgent the demand for sanitary reform; the well-conditioned streets and suburban localities are not sensibly injurious to health, under ordinary circumstances; and the question whether particular individuals will be benefitted by a country or a town residence, is a matter to be determined by the specialities of each case.

It may be contended by some persons that, however plausible much of the foregoing may appear, popular experience and medical prescriptions are alike opposed to the idea that towns, under any circumstances, are as healthy as the country. It may be said :- "See what happens when the body is exhausted, and the energies enfeebled, by protracted disease of almost every kind, the country invigorates and revives when medicine of every kind has only exhibited its powerlessness; the patient emaciated by fever, or other acute disease, but slowly convalesces till he removes from the town; the harassed dyspeptic consumes drugs and executes prescriptions innumerable, but finds no decided or enduring relief excepting in change from the air of a town to that of the country. Look, further, at the experience of persons not regarded as actually sick, how the appetite and the spirits, and the sleep, become improved during a brief sojourn some miles from the smoke of a city; nay, indeed, but notice the amelioration of health that will sometimes occur upon removal from a locality that is four miles from a town to one that is six." And so on : the illustration might be considerably extended.

The accuracy of such facts as the above may readily be conceded; they do not, however, affect the justice of my argument. In a large number of cases, it is undoubtedly true, that the physical qualities of the atmosphere as realized in certain rural districts, have an especially beneficial and curative action. In instances of exhaustion after acute disease, country air is almost essential to a sound recovery. Many unhealthy habits of body, moreover, are incorrigible by medicine, unless the patient breathe the purest atmosphere. It must yet be maintained, and the fact should never be lost sight of, that a leading element from which the advantages often flow, consists in the change of air; and think how much is comprehended within this well-used phraseology-temporary immunity from the ordinary cares of life, cessation of toil, daily recreation, novel scenes and agreeable society; circumstances all most conducive to the restoration of shattered nerves and broken health. Again and again have such agencies been seen to effect wonderful improvement in disease, 
even where the change, so far as physical conditions are concerned, may have been for the worse, from country to town. The influences which attach to novelty are exemplified once more. It is certain-and no matter how the fact is to be explained-that mere change of air sometimes is advantageous to health, irrespective of concomitant circumstances acting through the mind. It is the same thing with food, as every one knows. Let the most delicate and the most nutritious viands be habitually and uninterruptedly employed, and a change abstractedly for the worse, will not only be relished but will improve the digestion. The toujours perdrix is endurable by no one.

Hence it happens that change of air so often accomplishes good after medicines have been tried in vain. It is a superficial judgment, however, which ascribes to the place the benefits that really flow from the change. Disappointment has often resulted when this judgment has been acted upon. Permanent residences have been established in the charmed locality, whereupon the fallacy has been detected. The spell has not long survived the novelty. Nervousness, biliousness, and sleeplessness, you have found to vanish upon a fortnight's sojourn at the coast; but that this fact should receive its just interpretation, you must seek out the anxiousminded, disappointed, and over-wrought inhabitant of the favoured spot, and you will find that he suffers very much as you did before you left home. Take him back with you to town, make him forget himself, and regard the world without, interest him with strange sights and novel circumstances, and your own atmosphere, pestilential as you thought it, will also seem to have disclosed a health-restoring charm. A very little reflection upon these principles will discover their application in much of the experience of daily life.

I would guard myself against being misunderstood. Whatever may be the case with the great majority of mankind, there are, as before stated, exceptional instances of constant occurrence, where town and country are not indifferent as places of residence. The chest, for example, in certain individuals, constantly suffers in towns, whilst in other persons the brain and nervous system become disordered in the country, developing the phenomena of hysteria and hypochondriasis. In some instances the lungs in summer need, for their healthy action, the pure air of the country, and in the winter the more genial warmth and protection of a town. The same diversity of requirement obtains with regard to the nervous system. Some cases of disorded function are relieved by the bracing air, and free respiration, procurable in the country; and there are others rather benefitted by the social and exhilarating influences of large cities. It is very much the same thing with derangements of the stomach. There are cases in which abstinence is good, and there are others in which generous diet for a time becomes desiderated. But all exclusiveness and system here, as elsewhere, are to be aroided. There is a parallelism between vegetarianism and ultra-sanitary enthusiasm.

Neither the origin of diseases nor their modes of cure can be vigorously set forth in axiomatic phrase, neither can their doubtful points be elucidated by adoption of some favourite speculation of a particular era. As a matter of fact, however, the prominent idea of the day is very generally invoked to explain phenomena with which it is deemed to have some correspondence. In accordance with this circumstance, the fancied elucidation of disease and current systems of empiricism, are determined very much by the course of thought that happens to be predominant in the popular mind. In an age of witchcraft, maladies spring largely from magic, and are curable by amulets. In a later age, science displays the wonders of electricity, galvanism, and magnetism; these strike upon the imagination. At the same time certain ill-understood conditions and actions of the nerrous system engage the public attention; hereupon animal magnetism comes into fashion, is thought to shed light upon disease, and to furnish the means of cure. A fanatical teetotalism, ascribing diseases almost universally to alcoholic drinks, developes a water-cure of all saving efficacy. And in like manner the theory which would trace maladies without number to ash-pits, cess-pools, and streets, leads to a horror of towns, and would almost regard the country as Eden again realized. Such is the influence of ideas in their freshness: such is the power that attaches to novelty.

Diseases have certainly their origin in numerous other circumstances than those which mix themselves up with the dwelling-house; and the remedies, too, are correspondently diverse. Inherited fault in the constitution, vicious or defective diet, injudicious clothing, irregularity of life, and exposure to vicissitudes of temperature, constitute severally most prolific sources of ill health. Excessive thought, or mental idleness, violent passions, corroding grief, anxiety and suspense, and the common cares of life, form causes systematically productive of disease. In a community like the one in which we dwell, disappointments in business, and the anxieties of all kinds associated with it, are potent beyond expression in their undermining influence. I am very much inclined to think, that these latter circumstances, in some respects, exceed most other agencies in the destruction of health and the shortening of life.

There are diseases, moreover, which arise from the action of poisons; I do not refer to these in their proper forms, but to such as are subtle and not appreciable by the senses, and which produce epidemic and contagious diseases, and from which no sanitary improvement can furnish an absolute immunity. It is perfectly true that the virulence of most epidemics can be mitigated considerably by appropriate drainage and ventilation, but some will rage, and very destructively too, under every known physical condition. There certainly is not a more demonstrable fallacy than that which attributes diseases, like cholera and scarlet fever, to known and removable causes-a fallacy that has originated in the reasonings of persons having neither a medical education nor a medical experience, but one in which there is little or no participation amongst thinking members of the profession. Extended remarks, how. 
ever, upon this branch of the subject, would very unjustifiably encroach upon the time of the present anditory.

It is conformable to reason, and corresponds with the lessons of experience, that remedies for disease, and for enfeebled frames, must vary with the circumstances of the individual case. Good air and effective drainage are of the highest importance certainly, and I should be sorry to interpose a thought in seeming opposition to the ameliorations in these respects to which public opinion is leading. I do not, however, see that the discouragement of preposterous expectations can have any unfavourable tendency; on the contrary, I should rather believe that future disappointment which always follows upon over-wrought anticipation, would be much more likely to bring about prejudicial reaction than any attempt to establish more moderate views. At any rate it is right that the case should be justly stated, and in all that has preceded this has been my aim, whilst denouncing exaggeration and eliminating that which is false, to give greater distinctness to, and render more appreciable, the true.

\section{ON GOUTY AFFECTIONS OF THE EAR.}

BY WM. HARVEY, Esq., M.R.C.S.L.,

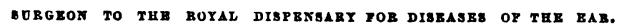

IN my last contribution on the "Rheumatic Affections of the Ear," I stated that there were some that partook more of the gouty diathesis, and in which the seizure commenced with tinnitus, and not unfrequently also attended with otorrhœa. This latter symptom was commonly presented to the surgeon under very aggravated forms in some cases, either from a wrong diagnosis, or from stimulating applications having been used. I am also of opinion that if the disease be early ascertained, and the constitutional symptoms treated more decidedly, it is much under the control of the surgeon. Those whose attention have been directed to this department of surgery, must frequently meet with this disease, either affecting the ear originally or from metastasis, the latter action more frequently, and thus it behoves the surgeon to treat the case actively, as the organ is soon irreparably lost. In the more chronic affection, or where it takes place in the aged, if diagnosed, much relief may be afforded to the distressing tinnitus. I have selected a few cases which will be appended to the second part of this paper, some of which I have been fortunate to trace to the termination.

Arthritic inflammation of the ear attacks chiefly the fibrous and nervous structures of the organ of hearing, and appears simultaneously or alternately with the manifestations of gout in other parts. It occurs, therefore, sometimes as a sympathetic affection of contiguous organs which may happen to be in the neighbourhood of the organ of hearing, and are attacked with gout, sometimes as the product of gouty metastasis.
Should the inflammation develop itself rather on the external division of the ear, the patient feels on the external ear increased warmth and an intolerable itching. The itching becomes constantly more insupportable, and at length passes into a burning, tearing, and pinching pain, which spreads on all sides over the entire circumference of the ear. In this case the patient complains of constant tinnitus, and occasional singing in the ear, and of hardness of hearing. These symptoms increase to a considerable degree after midnight, and become somewhat mitigated towards morning On examination the external ear presents an erysipelatous redness, feels hot, and is extremely sensitive to the touch. The entire surface of the meatus auditorius is found to present a redness, rather pale than dark, is entirely denuded of cerumen, or covered here and there with a dark brown, thin, and dried deposit of the same, and the membrana tympani of a dull appearance, traversed by some large vessels. Should the inflammation continue to remain at this low point, the epidermis of the meatus auditorius throws itself off in mealy scales or in larger portions, or becomes agglutinated with the cerumen of the ear, which now becomes secreted in more than the ordinary quality. If the inflammation becomes more intense, amid an exacerbation of pain, small abscesses or furuncles burst in the muscles of the ears and in the meatus, which eventually discharge a sanious pus. All inflammatory symptoms are gradually mitigated upon this, and are renewed only when an abscess makes its appearance. In old people there is observed simultaneously a considerable swelling, which spreads over the parotid and the mastoid process, is associated with a rose-coloured inflammation of the skin and cellular tissue, and prevents all motion of the lower-jaw. In weakly and cachectic subjects the parietes of the meatus present an œdematous swelling, and there sets in an obstinate mucous discharge. The discharge is somewhat thick, almost without odour, flows not constantly or equally profuse, but varies with respect to quantity. In damp or wet weather, and when the patients catch cold, the quantity is most considerable; when the atmosphere is dry and warm it is, on the contrary, very small. If the otorrhœa is of long duration, polypus growths may form. In case of frequent returns of the inflammation varicose vessels become developed on the membrana tympani, the membrane itself becomes turbid, assumes a dappled or spotted appearance, becomes thickened, and exhibits the look of a bit of patch-work. When gouty inflammation seizes on the middle ear, it is not rarely the reflection of an arthritic angina. If it have only a short course, and the inflammatory irritation is but small, the patient complains merely of dull pinching, and lacerating pains of the ear, which become exacerbated in cold and damp weather, and diminish in severity when the atmosphere is dry; he complains also of a sense of fulness and tension in the ear; of a buzzing, singing, and tinnitus in the ear, of indistinctness of hearing, and burning pain and dryness of the fauces. The Eustachian tube is commonly open, still air when pressed in enters only with some difficulty. If the inflammation rises to a higher degree, it commences 